\title{
Continuous venovenous hemodiafiltration with a low citrate dose regional anticoagulation protocol and a phosphate-containing solution: effects on acid-base status and phosphate supplementation needs
}

Santo Morabito ${ }^{1 *}{ }^{*}$, Valentina Pistolesi $^{1 \dagger}$, Luigi Tritapepe ${ }^{2}$, Elio Vitaliano ${ }^{3}$, Laura Zeppilli ${ }^{1}$, Francesca Polistena ${ }^{1}$, Enrico Fiaccadori ${ }^{4}$ and Alessandro Pierucci ${ }^{1}$

\begin{abstract}
Background: Recent guidelines suggest the adoption of regional citrate anticoagulation (RCA) as first choice CRRT anticoagulation modality in patients without contraindications for citrate. Regardless of the anticoagulation protocol, hypophosphatemia represents a potential drawback of CRRT which could be prevented by the adoption of phosphate-containing CRRT solutions. The aim was to evaluate the effects on acid-base status and phosphate supplementation needs of a new RCA protocol for Continuous Venovenous Hemodiafiltration (CWHDF) combining the use of citrate with a phosphate-containing CRRT solution.

Methods: To refine our routine $\mathrm{RCA}-\mathrm{CWH}$ protocol $\left(12 \mathrm{mmol} / \mathrm{I}\right.$ citrate, $\mathrm{HCO}_{3}^{-} 32 \mathrm{mmol} / /$ replacement fluid) (protocol A) and to prevent CRRT-related hypophosphatemia, we introduced a new RCA-CWHDF protocol (protocol B) combining an $18 \mathrm{mmol} / \mathrm{l}$ citrate solution with a phosphate-containing dialysate/replacement fluid $\left(\mathrm{HCO}_{3}^{-} 30 \mathrm{mmol} / \mathrm{l}\right.$, Phosphate 1.2). A low citrate dose $(2.5-3 \mathrm{mmo} / \mathrm{l})$ and a higher than usual target circuit- $\mathrm{Ca}^{2+}(\leq 0.5 \mathrm{mmol} / \mathrm{l})$ have been adopted.

Results: Two historical groups of heart surgery patients $(n=40)$ underwent RCA-CRRT with protocol $A(n=20,102$ circuits, total running time 5283 hours) or protocol $B(n=20,138$ circuits, total running time 7308 hours). Despite higher circuit-Ca $^{2+}$ in protocol $B(0.37$ vs $0.42 \mathrm{mmol} / \mathrm{l}, \mathrm{p}<0.001$ ), circuit life was comparable (51.8 \pm 36.5 vs $53 \pm 32.6$ hours). Protocol $A$ required additional bicarbonate supplementation $(6 \pm 6.4 \mathrm{mmol} / \mathrm{h})$ in $90 \%$ of patients while protocol $B$ ensured appropriate acid-base balance without additional interventions: $\mathrm{pH} 7.43$ (7.40-7.46), Bicarbonate 25.3 (23.8-26.6) mmol//, BE $0.9(-0.8$ to +2.4); median (IQR). No episodes of clinically relevant metabolic alkalosis, requiring modifications of RCA-CRRT settings, were observed. Phosphate supplementation was needed in all group A patients (3.4 $\pm 2.4 \mathrm{~g} /$ day) and in only $30 \%$ of group B patients $(0.5 \pm 1.5 \mathrm{~g} /$ day). Hypophosphatemia developed in $75 \%$ and $30 \%$ of group $A$ and group B patients, respectively. Serum phosphate was significantly higher in protocol $B$ patients $(P<0.001)$ and, differently to protocol $A$, appeared to be steadily maintained in near normal range $(0.97-1.45 \mathrm{mmol} / \mathrm{l}, \mathrm{IQR})$.
\end{abstract}

Conclusions: The proposed RCA-CWHDF protocol ensured appropriate acid-base balance without additional interventions, providing prolonged filter life despite adoption of a higher target circuit- $\mathrm{Ca}^{2+}$. The introduction of a phosphate-containing solution, in the setting of RCA, significantly reduced CRRT-related phosphate depletion.

Keywords: AKI, Citrate, CRRT, CWH, CWHDF, Hypophosphatemia, Regional citrate anticoagulation

\footnotetext{
* Correspondence: santo.morabito@uniroma1.it

${ }^{\dagger}$ Equal contributors

'Department of Nephrology and Urology, Hemodialysis Unit, Umberto I,

Policlinico di Roma, "Sapienza" University, Rome, Italy

Full list of author information is available at the end of the article
} 


\section{Background}

Continuous renal replacement therapy (CRRT) is the most widely adopted technique for the treatment of acute kidney injury (AKI) in the critically ill [1-3] and it is well known that the need for prolonged anticoagulation still represents its main drawback [4-6]. Indeed, although the incidence of bleeding complications in patients undergoing renal replacement therapy (RRT) can be extremely variable among different studies, the risk of major bleeding during standard anticoagulation with heparin should be strongly considered [5,7]. Among different options, regional citrate anticoagulation (RCA) has been increasingly suggested as a safe and efficacious alternative to standard heparin anticoagulation during CRRT [8-19].

Citrate provides anticoagulation in the extracorporeal circuit by chelation of ionized calcium [8], which is required as a key cofactor in several steps of the clotting cascade [20]. A citrate solution is infused before the filter, being the citrate dose titrated to maintain ionized calcium levels in the extracorporeal circuit below 0.3$0.4 \mathrm{mmol} / \mathrm{l}$. Part of the infused citrate is removed by the treatment itself, depending on its operative settings; citrate returning to the patient is rapidly metabolized by the liver and the skeletal muscle in the Krebs' cycle, with an ensuing bicarbonate production which provides a buffer supply to the patient [8]. On these bases, the citrate metabolic load for the patient is the difference between the delivered dose of citrate and the amount of citrate lost in the effluent [21]. Therefore, different combinations of citrate solutions and replacement fluids for CRRT, as well as the operational parameters setting peculiar of each RRT modality, might be associated with a high variability of buffers supply, thus significantly affecting the acid-base status of the patient [22-24].

Hypophosphatemia is a known issue of CRRT reported in up to $80 \%$ of cases when standard CRRT solutions are used [25-30], especially if high dialysis doses are delivered [26,27]. RRT-related phosphate depletion should be avoided in critically ill patients and the adoption of phosphate-containing CRRT solutions could be helpful to reduce the incidence of hypophosphatemia and/or to minimize the need for parenteral phosphorus supplementation [24,25,28,30,31].

In the present study we evaluated the effects on acidbase status and serum phosphate levels of a new RCA protocol for Continuous Venovenous Hemodiafiltration (CVVHDF) using an $18 \mathrm{mmol} / \mathrm{l}$ citrate solution in combination with a phosphate-containing solution, acting as dialysate and replacement fluid. The new protocol was introduced with the following targets: a) to refine buffers balance of a previously adopted RCA protocol for Continuous Venovenous Hemofiltration (CVVH), based on a $12 \mathrm{mmol} / \mathrm{l}$ citrate solution combined with a conventional replacement fluid; b) to prevent CRRT-related phosphate depletion; c) to maintain a low citrate dose, adopting a higher than usual target circuit ionized calcium.

\section{Methods}

In this observational study, data prospectively collected from May 2010 to December 2012 have been analysed to compare a previously adopted RCA-CVVH protocol with a newly designed RCA-CVVHDF protocol in two historical groups of patients who consecutively underwent CRRT for AKI following major heart surgery at the Cardiac Surgery ICU of Policlinico Umberto I, "Sapienza" University (Rome, Italy). Only patients treated for at least 72 hours have been included in the analysis. The study was in agreement with the Declaration of Helsinki and informed consent was obtained from either the patient or a close relative. Ethics Committee approval was not required for this observational study because the patients, included in a retrospective analysis of prospectively collected data, were not discretionally assigned to different medical interventions. Indeed, in this study we report, in two groups of patients who underwent RCA-CRRT in subsequent historical periods, the effects of the change of our routine RCA protocol after commercial availability of new solutions, registered in our country for specific use in CRRT. At our institution, RCA is the standard anticoagulation method in high bleeding risk heart surgery patients undergoing CRRT and data collection, as well as RCA protocols, are part of our routine medical procedures. Starting from April 2012, according to KDIGO Clinical Practice Guideline for AKI [6] and regardless of the coagulation status, the adoption of RCA was extended to all patients undergoing CRRT without contraindications for citrate.

Until September 2011, RCA was performed in CVVH modality with a $12 \mathrm{mmol} / \mathrm{l}$ pre-dilution citrate solution (trisodium citrate $10 \mathrm{mmol} / \mathrm{l}$, citric acid 2, $\mathrm{Na}^{+} 136, \mathrm{Cl}^{-}$ 106; Prismocitrate 10/2, Gambro, Sondalo, Italy) and a calcium-containing post-dilution replacement fluid with bicarbonate $\left(\mathrm{HCO}_{3}^{-} 32 \mathrm{mmol} / \mathrm{l}, \mathrm{Ca}^{2+} 1.75, \mathrm{Mg}^{2+} 0.5, \mathrm{~K}^{+}\right.$ 2, $\mathrm{Na}^{+}$140, $\mathrm{Cl}^{-}$111.5; Prismasol 2, Gambro, Sondalo, Italy) (Protocol A) (Figure 1) [19]. In case of worsening metabolic acidosis, not related to citrate accumulation and persisting after RCA-CVVH parameters optimization, additional bicarbonate infusion in a separate line was started according to ICU physician's judgement. In order to optimize buffers balance and to possibly reduce the need for phosphorus supplementation, we implemented a new protocol (Protocol B) adopting the following solutions, recently introduced in Europe: $18 \mathrm{mmol} / \mathrm{l}$ pre-dilution citrate solution (trisodium citrate $18 \mathrm{mmol} /$ l, $\mathrm{Na}^{+}$140, $\mathrm{Cl}^{-}$86; Prismocitrate 18/0, Gambro) combined with a calcium- and phosphate-containing 

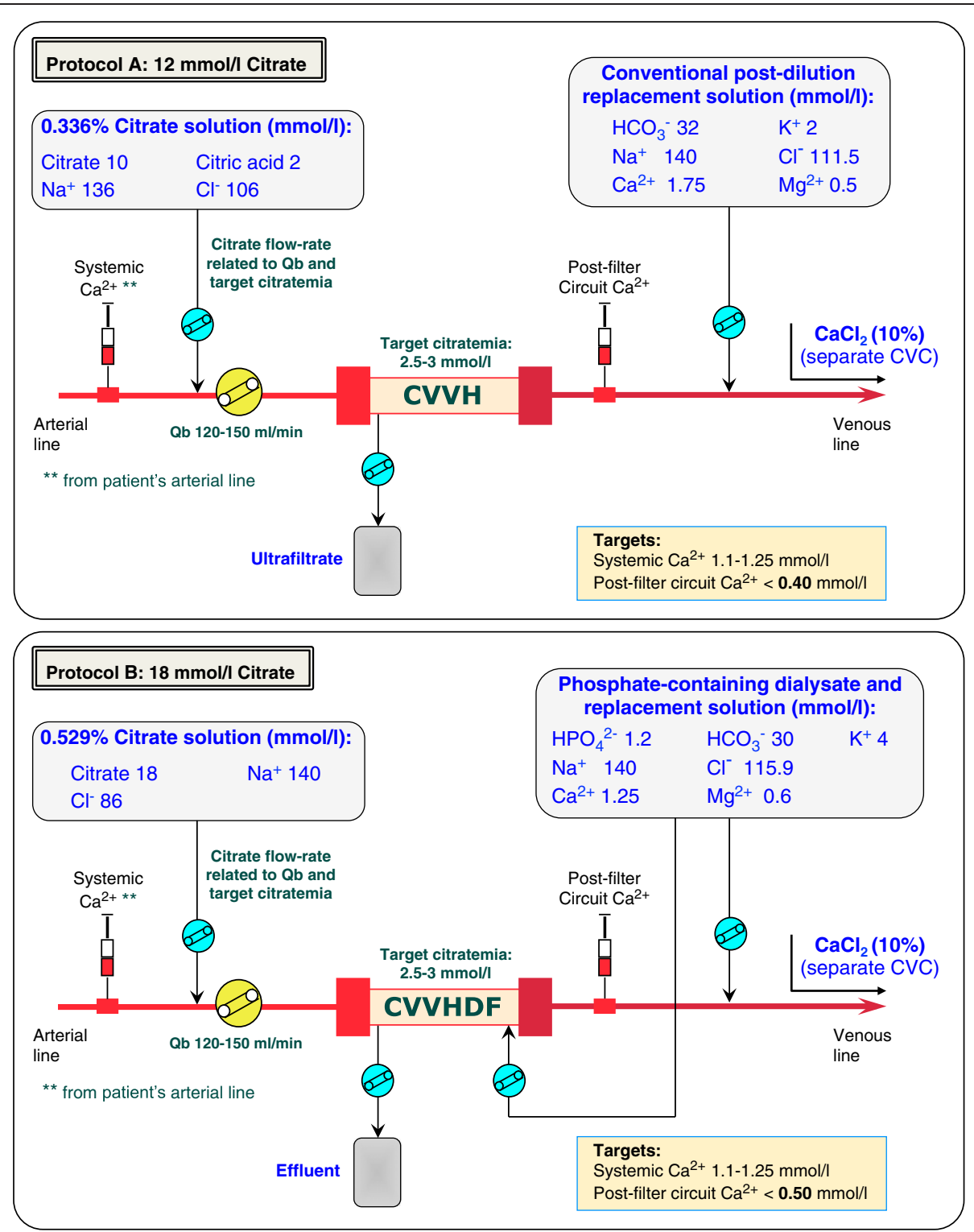

Figure 1 Pre-post dilution RCA-CVVH and RCA-CVVHDF circuits. Schematic representation of the RCA extracorporeal circuits reporting the composition of the solutions respectively adopted in protocol A (top panel) and protocol B (bottom panel)

solution, acting as dialysate as well as post-dilution replacement fluid $\left(\mathrm{HPO}_{4}^{2-} 1.2 \mathrm{mmol} / \mathrm{l}, \mathrm{HCO}_{3}^{-} 30, \mathrm{Ca}^{2+}\right.$ $1.25, \mathrm{Mg}^{2+} 0.6, \mathrm{~K}^{+} 4, \mathrm{Na}^{+} 140, \mathrm{Cl}^{-} 115.9$; Phoxilium, Gambro) (Figure 1). The CVVHDF modality has been preferred with the aim to maintain a low filtration fraction. The protocol has been designed through a mathematical model developed to roughly estimate metabolic citrate load, buffers balance (citrate and bicarbonate), effluent calcium loss, as well as the main RCA-CRRT parameters. The model, included in a database software (FileMaker Inc, Santa Clara, CA, USA), and compatible with many portable devices, allowed to easily making calculations at the bedside. Input fields: blood flow rate $(\mathrm{ml} / \mathrm{min})$, citrate solution concentration $(\mathrm{mmol} / \mathrm{l})$, citrate solution flow rate $(\mathrm{l} / \mathrm{h})$, bicarbonate and ionized calcium dialysate and/or replacement solution concentration $(\mathrm{mmol} / \mathrm{l})$, dialysate flow rate $(\mathrm{l} / \mathrm{h})$, post-dilution flow rate $(\mathrm{l} / \mathrm{h})$, patient's bicarbonate and ionized calcium $(\mathrm{mmol} / \mathrm{l})$, patient's hematocrit $(\%)$ and serum protein $(\mathrm{g} / \mathrm{dl})$, net ultrafiltration rate $(\mathrm{l} / \mathrm{h})$. Calculated output fields (corrected for pre-dilution when appropriate): pre-filter estimated citrate blood concentration $(\mathrm{mmol} / \mathrm{l})$ calculated in plasma water [(citrate solution concentration $\times$ citrate flow rate)/(citrate flow rate + plasma water flow rate)], total effluent rate $(\mathrm{l} / \mathrm{h})$, filtration fraction (\%), estimated citrate metabolic load $(\mathrm{mmol} / \mathrm{h})$ [(citrate solution concentration $\times$ citrate flow rate) - (effluent rate $\times$ estimated citrate blood concentration $\times$ SC)], CRRT buffers and 
calcium balance (mmol), suggested $\mathrm{CaCl}_{2}$ infusion rate $(\mathrm{ml} / \mathrm{h})$.

CRRT was performed using the Prismaflex system (Gambro Lundia AB, Lund, Sweden) and PAES hemofilters (HF 1000, $1.15 \mathrm{~m}^{2}$, Gambro, Meyzieu, France). Vascular access was obtained by cannulation of the internal jugular or femoral vein with a double lumen polyurethane catheter ( $\oslash 12$ French). In relation to blood flow rate, the citrate solution flow rate was initially set to meet a roughly estimated target circuit citrate concentration of $2.5-3 \mathrm{mmol} / \mathrm{l}$, calculated in plasma water $[32,33]$. For protocol $A$, citrate flow rate was modified, if needed, to achieve a circuit $\mathrm{Ca}^{2+}\left(\mathrm{c}-\mathrm{Ca}^{2+}\right) \leq 0.4 \mathrm{mmol} / \mathrm{l}$. For protocol $B$, taking into account the combination of a more concentrated citrate solution with a $30 \mathrm{mmol} / \mathrm{l} \mathrm{bi-}$ carbonate dialysate/replacement fluid, we accepted a higher than usual c-Ca ${ }^{2+}$ target of $\leq 0.5 \mathrm{mmol} / \mathrm{l}$ with the aim to maintain a low citrate dose and to prevent the occurrence of metabolic alkalosis related to buffer overload. In protocol B (CVVHDF), dialysate flow was maintained at the fixed rate of $500 \mathrm{ml} / \mathrm{h}$. Post-dilution flow rate (Prismasol 2 for protocol $A$, Phoxilium for protocol $B$ ) was adjusted to achieve a prescribed dialysis dose, corrected for pre-dilution [correction factor $=$ blood flow rate/(blood flow rate + Pre-dilution infusion rate)], of at least $25 \mathrm{ml} / \mathrm{kg} / \mathrm{h}$. Calcium chloride (10\%) was infused in a separate central venous line to maintain a target systemic $\mathrm{Ca}^{2+}\left(\mathrm{s}-\mathrm{Ca}^{2+}\right)$ of $1.1-1.25 \mathrm{mmol} / \mathrm{l}$, measured by arterial blood gases at least every 4 hours. A total calcium/ $\mathrm{Ca}^{2+}$ ratio (Calcium Ratio) > 2.5 was considered an indirect sign of citrate accumulation [34]. Serum electrolytes, coagulation parameters and complete blood count were daily assessed.

By convention, hypophosphatemia was defined as follows: mild $(<0.81 \mathrm{mmol} / \mathrm{l})$, moderate $(<0.61 \mathrm{mmol} / \mathrm{l})$ and severe $(<0.32 \mathrm{mmol} / \mathrm{l})$ [30]. Nutritional support was provided mainly via parenteral route associated, if tolerated, with enteral route; energy and protein intake targets were $25 \mathrm{Kcal} / \mathrm{Kg} /$ day and $1.5 \mathrm{~g} / \mathrm{Kg} /$ day with a phosphorus intake of about $20-30 \mathrm{mmol} /$ day during both protocol periods. Potassium, phosphate and magnesium losses with CRRT were replaced, when needed, respectively with potassium chloride, d-fructose-1,6-diphosphate (FDP; Esafosfina $5 \mathrm{~g} / 50 \mathrm{ml}$ ) and magnesium sulphate. In particular, FDP administration was scheduled in case of phosphate levels $<0.9 \mathrm{mmol} / \mathrm{l}$. Acid-base parameters, $\mathrm{K}^{+}$and $\mathrm{Ca}^{2+}$ were measured by arterial blood gases analyzer (GEM Premiere 4000, Instrumentation Laboratory UK Ltd, Warrington, UK) at least every 4 hours. Clinically relevant metabolic alkalosis was arbitrarily defined as a persistent increase of $\mathrm{pH}>7.50$ and bicarbonate $>30 \mathrm{mmol} / \mathrm{l}$.

The causes for CRRT stopping were reported after an accurate evaluation of monitor events and pressure alarms, recorded on the Prismaflex memory card. CRRT interruption due to coagulation was defined as an overt sign of circuit clotting, or as a $100 \%$ increase of filter drop pressure (difference between pre-filter and post-filter hydrostatic pressure). CRRT interruption for clinical reasons (i.e., evaluation of renal function recovery, patient mobilization, etc.), unrelated to circuit clotting, was classified and reported as scheduled CRRT stopping.

\section{Statistical analysis}

Data are reported as mean \pm standard deviation (SD) or as median and interquartile range (IQR). Statistical analysis for continuous variables was made by one-way ANOVA or Student t-test. Non-parametric analysis was performed, when appropriate, using the Mann-Whitney $\mathrm{U}$ test for independent samples. Categorical variables were analysed with chi-square test or Fisher exact test. Circuit lifetime was evaluated with Kaplan-Meier survival analysis and survival curves distribution was compared with the Log Rank (Mantel-Cox) test. All tests were 2-sided (significance level 5\%). IBM SPSS statistical software (19.0, SPSS Inc., USA) was used for all analysis.

\section{Results}

Twenty patients underwent RCA-CVVH with protocol $A$ while, after introduction of the new protocol, 20 patients were treated with RCA-CVVHDF according to protocol $B$. Clinical characteristics of the patients at the time of starting CRRT have been compared and reported for both groups in Table 1. Among RCA-CRRT initial parameters, reported in Table 2, prescribed dialysis dose, corrected for pre-dilution, as well as citrate dose, were comparable.

One hundred and two circuits (total running time 5283 hours) were used during protocol $A$ period while 138 circuits (total running time 7308 hours) were used after adoption of protocol B. Filter life was $51.8 \pm 36.5$ and $53 \pm 32.6$ hours, respectively $(\mathrm{P}=0.796)$ (Table 3 ).

RCA-CRRT stopping causes and circuits running at 24, 48, 72 hours are reported in Table 3 . Considering all circuits $(\mathrm{n}=240)$, filter clotting was the less frequent cause for RCA-CRRT interruption (3.7\%). In particular, during protocol $A, \mathrm{RCA}-\mathrm{CVVH}$ didn't stop in any case for filter clotting while $6.5 \%$ of protocol $B$ CRRT sessions were stopped for significant increments of filter drop pressure $(>100 \%) \quad(\mathrm{P}=\mathrm{ns})$. Overall, pressure alarms handling, related to CVC malfunction, was the most frequent cause of CRRT stopping (37.1\%). Kaplan-Meier curves of circuit lifetime probability, derived from analysis of scheduled and unscheduled CRRT stoppings for any cause, showed no difference between the two protocols (Figure 2).

Calcium monitoring parameters, including $\mathrm{C}^{-\mathrm{Ca}^{2+}}$, $\mathrm{s}-\mathrm{Ca}^{2+}$ and Calcium Ratio for each patient at different 
Table 1 Clinical characteristics of the patients at CRRT start

\begin{tabular}{|c|c|c|c|}
\hline Variable & $\begin{array}{c}\text { Protocol A } \\
(n=20)\end{array}$ & $\begin{array}{l}\text { Protocol B } \\
(n=20)\end{array}$ & $P$ value \\
\hline Female gender & $7 / 20(35 \%)$ & $4 / 20(20 \%)$ & 0.480 \\
\hline Age, years & $72(69-77)$ & $70(59-73)$ & 0.073 \\
\hline Body weight, $\mathrm{kg}$ & $72(67-79)$ & $70(66-80)$ & 0.715 \\
\hline Oliguric AKI ${ }^{\S}$ & $90 \%$ & $75 \%$ & 0.407 \\
\hline Mean arterial pressure, mmHg & $70(70-80)$ & $70(62-80)$ & 0.399 \\
\hline Use of vasopressors or inotropes & $75 \%$ & $85 \%$ & 0.695 \\
\hline Mechanical ventilation & $85 \%$ & $90 \%$ & 0.633 \\
\hline Artificial nutrition & $95 \%$ & $100 \%$ & 0.311 \\
\hline APACHE II score & $32(29-35)$ & $32(27-35)$ & 0.307 \\
\hline SOFA score & $15(12-16)$ & $13(9-14)$ & 0.056 \\
\hline SOFA cardio-vascular score & $3(2-3)$ & $3(2-3)$ & 0.130 \\
\hline Serum creatinine, mg/dl & $2.10(1.75-3.00)$ & $2.25(1.75-2.85)$ & 0.469 \\
\hline Blood urea nitrogen, mg/dl & $40.5(26.9-62.0)$ & $40.5(29.0-55.2)$ & 0.978 \\
\hline Hemoglobin, g/dl & $10.9(9.9-11.2)$ & $10.0(8.8-10.9)$ & 0.084 \\
\hline Hematocrit,\% & $32.1(31.2-33.4)$ & $31.6(27.5-34.5)$ & 0.419 \\
\hline White blood cells, $\times 10^{3} / \mu \mathrm{l}$ & $11.0(8.2-15.9)$ & $12.4(11.0-16.5)$ & 0.664 \\
\hline Platelet count, $\times 10^{3} / \mu \mathrm{l}$ & $93(76-177)$ & $161(98-254)$ & 0.043 \\
\hline Antithrombin III activity,\% & $70(63-78)$ & $61(49-78)$ & 0.250 \\
\hline APTT Ratio & $1.4(1.3-1.9)$ & $1.6(1.4-2)$ & 0.358 \\
\hline Sodium, mmol/l & $139(134-140)$ & $139(137-143)$ & 0.110 \\
\hline Potassium, mmol// & $4.3(4.0-4.8)$ & $4.2(4.1-4.8)$ & 0.762 \\
\hline Total Calcium, mmol/l & $2.16(1.95-2.30)$ & $2.03(1.93-2.19)$ & 0.166 \\
\hline Phosphorus, mmol/l & $1.40(1.07-1.58)$ & $1.38(1.16-1.70)$ & 0.897 \\
\hline Magnesium, mmol// & $0.85(0.75-0.93)$ & $0.78(0.74-0.97)$ & 0.572 \\
\hline $\mathrm{pH}$, units & $7.38(7.35-7.41)$ & $7.40(7.38-7.43)$ & 0.324 \\
\hline Bicarbonate, mmol/l & $21.8(21.0-22.6)$ & $22.2(21.0-24.2)$ & 0.535 \\
\hline Base Excess & $-3.5(-4.0$ to -2.0$)$ & $-1.0(-4.0$ to 1.0$)$ & 0.316 \\
\hline $\mathrm{pCO}_{2}, \mathrm{mmHg}$ & $38(36-42)$ & $37(33-40)$ & 0.992 \\
\hline Lactate, mmol/l & $1.4(1.0-3.0)$ & $1.4(1.2-2.4)$ & 0.879 \\
\hline Bilirubin, mg/dl & $0.89(0.62-1.45)$ & $0.73(0.46-1.37)$ & 0.376 \\
\hline Aspartate aminotransferase, IU/I & $89(29-608)$ & $97(49-376)$ & 0.800 \\
\hline Alanine aminotransferase, IU/I & $37(12-325)$ & $26(18-75)$ & 0.970 \\
\hline Albumin, g/dl & $2.6(2.4-2.8)$ & $2.45(2.2-2.9)$ & 0.820 \\
\hline Heart surgery: & & & Overall \\
\hline Coronary artery bypass grafting & $25 \%$ & $35 \%$ & $30 \%$ \\
\hline $\begin{array}{l}\text { Coronary artery bypass } \\
\text { grafting + valvular surgery }\end{array}$ & $40 \%$ & $15 \%$ & $27.5 \%$ \\
\hline Valvular surgery & $25 \%$ & $20 \%$ & $22.5 \%$ \\
\hline Ascending aorta replacement & $10 \%$ & $30 \%$ & $20 \%$ \\
\hline
\end{tabular}

Data are expressed as median (IQR) or percentage. ${ }^{\S}$ According to AKIN criteria (Crit Care 2007; 11:R31).

treatment days, are displayed in Figure 3. Circuit $\mathrm{Ca}^{2+}$ was maintained in the target range adopted for protocol $A$ and protocol $B$ and was significantly higher during RCA-CVVHDF with protocol $B$ (median 0.37 vs $0.42 \mathrm{mmol} / \mathrm{l}, \mathrm{P}<0.001$ ) (Table 4 ). With both protocols, $\mathrm{s}-\mathrm{Ca}^{2+}$ was steadily maintained in normal range with few modifications of $\mathrm{CaCl}_{2}$ flow rate (1-2 within 24 hours),
Table 2 Initial RCA-CRRT settings

\begin{tabular}{|c|c|c|c|}
\hline RCA-CRRT settings & Protocol A & Protocol B & P-value \\
\hline $\begin{array}{l}\text { Prescribed dialysis dose }{ }^{\S}, \\
\mathrm{ml} / \mathrm{kg} / \mathrm{h}\end{array}$ & $28.25(26.69-29.66)$ & $26.67(25.69-28.88)$ & 0.333 \\
\hline Blood flow rate, $\mathrm{ml} / \mathrm{min}$ & $130(130-140)$ & $140(140-140)$ & 0.083 \\
\hline $\begin{array}{l}\text { Pre-dilution citrate solution } \\
\text { flow rate, } 1 / \mathrm{h}\end{array}$ & $1.56(1.50-1.68)$ & $1.00(1.00-1.00)$ & $<0.001$ \\
\hline Pre-dilution,\% & $16.67(16.58-16.67)$ & $10.64(10.64-10.64)$ & $<0.001$ \\
\hline $\begin{array}{l}\text { Post-dilution replacement } \\
\text { fluid flow rate, } 1 / \mathrm{h}\end{array}$ & $0.80(0.80-0.95)$ & $0.60(0.55-0.80)$ & $<0.001$ \\
\hline Dialysate flow rate, $1 / \mathrm{h}$ & N/A & $0.50(0.50-0.50)$ & - \\
\hline Filtration Fraction,\% & $38.4(34.5-40.3)$ & $27.0(25.7-28.8)$ & $<0.001$ \\
\hline $\begin{array}{l}10 \% \text { Calcium chloride infusion } \\
\text { rate, } \mathrm{mmol} / \mathrm{h}\end{array}$ & $2.00(1.60-2.10)$ & $1.90(1.36-2.28)$ & 0.344 \\
\hline Citrate infusion rate, $\mathrm{mmol} / \mathrm{h}$ & $18.70(18.00-20.15)$ & $18.00(18.00-18.00)$ & 0.051 \\
\hline Estimated citrate load, mmol/h & $12.34(11.74-13.92)$ & $12.35(12.05-12.65)$ & 0.471 \\
\hline Estimated citrate dose, mmol// & $2.84(2.74-2.91)$ & $2.83(2.76-2.95)$ & 0.618 \\
\hline
\end{tabular}

Data are expressed as median (IQR). ${ }^{\S}$ Corrected for pre-dilution.

without episodes of hypocalcemia or hypercalcemia (Figure 3). The amount of $\mathrm{CaCl}_{2}$ required to maintain $\mathrm{s}-\mathrm{Ca}^{2+}$ in the target range was comparable $(\mathrm{P}=0.800)$ (Table 4).

Acid-base parameters and the main serum electrolytes for both groups of patients are reported in Table 4. Serum bicarbonate levels and $\mathrm{pH}$ values were significantly higher in protocol $B$ patients $(\mathrm{P}<0.001)$, without the need for additional bicarbonate infusion, which was otherwise required in 18 out of 20 protocol $A$ patients $\left(\mathrm{NaHCO}_{3}\right.$ infusion rate $\left.6 \pm 6.4 \mathrm{mmol} / \mathrm{h}\right)$. No episodes of clinically relevant metabolic alkalosis, requiring additional intervention on RCA-CRRT settings, were observed with both protocols. In particular, during protocol $B, \mathrm{pH}$ values resulted $\geq 7.50$ in $3.8 \%$ of determinations (63 out of 1664) with a Base Excess $\geq 5$ in $3.2 \%$ of determinations (54 out of 1664). Acid-base parameters

Table 3 Circuit lifetime and CRRT interruption causes

\begin{tabular}{|c|c|c|c|}
\hline & $\begin{array}{l}\text { Protocol A } \\
(n=102)\end{array}$ & $\begin{array}{l}\text { Protocol B } \\
(n=138)\end{array}$ & $\begin{array}{l}\text { Overall } \\
(n=240)\end{array}$ \\
\hline \multicolumn{4}{|l|}{ CIRCUIT LIFETIME } \\
\hline Mean $\pm S D, h$ & $51.8 \pm 36.5$ & $53 \pm 32.6$ & $52.5 \pm 34.2$ \\
\hline Median (IQR), h & $44.5(24.0-72.0)$ & $47.5(24.0-78.5)$ & $47.5(24.0-75.0)$ \\
\hline$>24 \mathrm{~h}$ & $77 \%$ & $76 \%$ & $76.7 \%$ \\
\hline$>48 \mathrm{~h}$ & $50 \%$ & $50 \%$ & $50 \%$ \\
\hline$>72 \mathrm{~h}$ & $28 \%$ & $33 \%$ & $31.2 \%$ \\
\hline \multicolumn{4}{|l|}{ CRRT STOPPING CAUSES } \\
\hline CVC malfunction, n (\%) & $40(39.2 \%)$ & 49 (35.5\%) & $89(37.1 \%)$ \\
\hline $\begin{array}{l}\text { Alarm handling/ technical } \\
\text { issues, n (\%) }\end{array}$ & $26(25.4 \%)$ & $31(22.5 \%)$ & $57(23.8 \%)$ \\
\hline Scheduled, n (\%) & $24(23.6 \%)$ & $36(26.1 \%)$ & $60(25 \%)$ \\
\hline Medical procedures, n (\%) & $12(11.8 \%)$ & $13(9.4 \%)$ & $25(10.4 \%)$ \\
\hline Clotting, n (\%) & $0(0 \%)$ & $9(6.5 \%)$ & $9(3.7 \%)$ \\
\hline
\end{tabular}

Data are expressed as mean \pm SD or median (IQR) or percentage. 


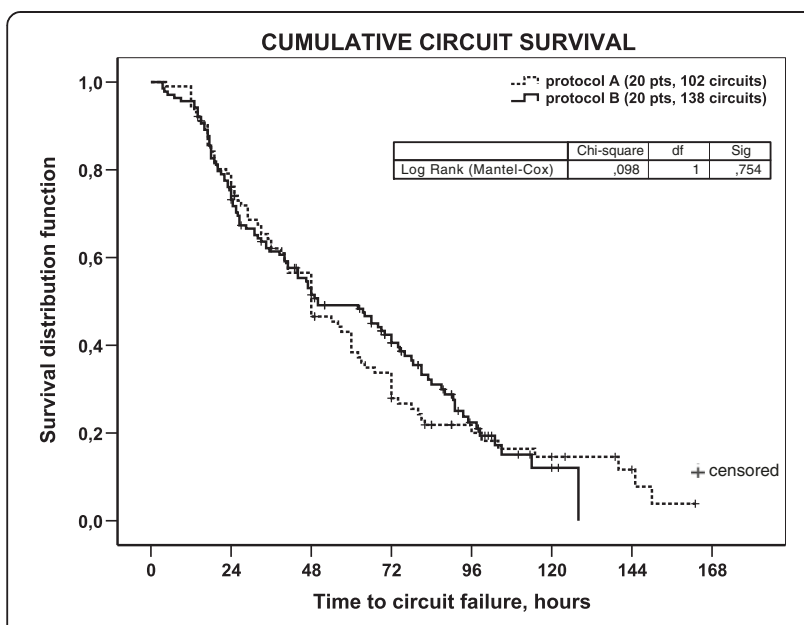

Figure 2 Kaplan-Meier curves of circuit lifetime probability according to the two RCA protocols. Survival curves, derived from the analysis of scheduled and unscheduled CRRT stopping for any cause, have been compared with the Log Rank (Mantel-Cox) test ( $p=0.754)$.

throughout RCA-CRRT days, including values of $\mathrm{pH}$, bicarbonate and Base Excess for each patient at different treatment days, are displayed in Figure 4. Regardless of the RCA-CRRT protocol, no episodes of metabolic acidosis, possibly related to inadequate citrate metabolism, were observed and Calcium Ratio resulted constantly below the accepted threshold value of 2.5 .

At some times during RCA-CRRT, 75\% of protocol $A$ patients developed hypophosphatemia ( 6 mild, 9 moderate), otherwise observed in only $30 \%$ of protocol $B$ patients $(4$ mild, 2 moderate) $(\mathrm{P}<0.001)$. In particular, 89 out of 206 phosphorus level determinations met the definition criteria for mild to moderate hypophosphatemia during protocol $A$ (42 mild, 47 moderate) while a significantly lower number of determinations (26 out of 334; $\mathrm{P}<0.001)$ revealed episodes of hypophosphatemia during protocol $B$ (19 mild, 7 moderate). Protocol $A$ required phosphorus supplementation (FDP $3.39 \pm 2.45 \mathrm{~g} /$ day) in all patients. A lower amount of phosphorus supplementation (FDP $0.52 \pm 1.53 \mathrm{~g} /$ day) was needed in 6 out of 20 patients (30\%) undergoing protocol $B$. Serum phosphate was significantly higher in protocol $B$ patients $(\mathrm{P}<0.001)$ and, differently to protocol $A$, it appeared to be steadily maintained in near normal range (IQR $0.97-1.45 \mathrm{mmol} / \mathrm{l}$ ) without episodes of hyperphosphatemia requiring modifications of CRRT settings (Table 4). Serum phosphate levels throughout RCA-CRRT days are displayed in Figure 5 for both protocols.

Clinically relevant hypomagnesemia has been prevented in all patients by magnesium sulphate supplementation (2 to $3 \mathrm{~g} /$ day) (Table 4 ). Serum potassium was steadily maintained in normal range with both protocols. As expected, the need for potassium chloride supplementation was significantly lower with protocol $B(\mathrm{P}<0.001)$ (Table 4$)$.
During RCA-CRRT no patients had bleeding complications and overall transfusion rate was $0.33 \pm 0.23$ blood units/day (median 0.24, IQR 0.18-0.43), without differences between the two groups $(0.32 \pm 0.2$ versus $0.33 \pm$ $0.26, \mathrm{P}=0.704)$. Overall, thirty-day survival was $67.5 \%$ while survival at discharge from the hospital was $57.5 \%$. At the time of discharge, renal function recovery, allowing to stop RRT, was observed in 9 out of 11 survivors of protocol A patients $(81.8 \%)$ and in 10 out of 12 survivors of protocol B patients (83.3\%).

\section{Discussion}

The need for continuous anticoagulation represents a potential drawback of CRRT modalities [4-6]. Recently published guidelines suggest the adoption of RCA as first choice CRRT anticoagulation modality in patients without contraindications for citrate, especially in the presence of increased bleeding risk [6].

At our institution, RCA is now routinely adopted in heart surgery patients undergoing CRRT with the aim to minimize bleeding complications. In the present study, both RCA protocols allowed to maintain low transfusion rates in a small cohort of selected high bleeding risk patients, ensuring an adequate filter life with a very low incidence of clotting as cause of CRRT stopping (9 out of 240 CRRT sessions). In particular, the use of a low flow rate calcium-containing dialysate, which characterizes protocol B, didn't appear to adversely affect mean filter life. Regarding the clotting events observed in a small proportion of protocol $\mathrm{B}$ circuits, it is tempting to speculate that this finding could be explained by the strategy to allow higher levels of $\mathrm{Ca}^{2+}$ inside the circuit, although the possible role of the significantly higher platelet count should be considered. On the other side, this potential drawback of protocol B could be counterbalanced by the advantage of a more easy maintenance of a low citrate dose $(2.5-3 \mathrm{mmol} / \mathrm{l}$ in plasma water). In this regard, taking into consideration that any strategy aimed to prevent citrate accumulation should be targeted to decrease citrate infusion rate [35], both protocols have been designed with the aim to minimize citrate load, with a resulting citrate dose among the lowest until now reported. Regardless of the RCA protocol adopted, no episodes of high anion gap metabolic acidosis, possibly related to inadequate citrate metabolism, were observed. Indeed, the Calcium Ratio, commonly accepted as a useful index of citrate accumulation $[34,36,37]$ and recently reported as an independent predictor of clinical outcome [38], resulted steadily below the conventional threshold value of 2.5 in all patients. On the other hand, the buffers mass balance obtained with protocol $A$, based on a $12 \mathrm{mmol} / \mathrm{l}$ citrate solution, was frequently associated with a suboptimal buffers supply despite optimization of RCA-CVVH operative parameters. 


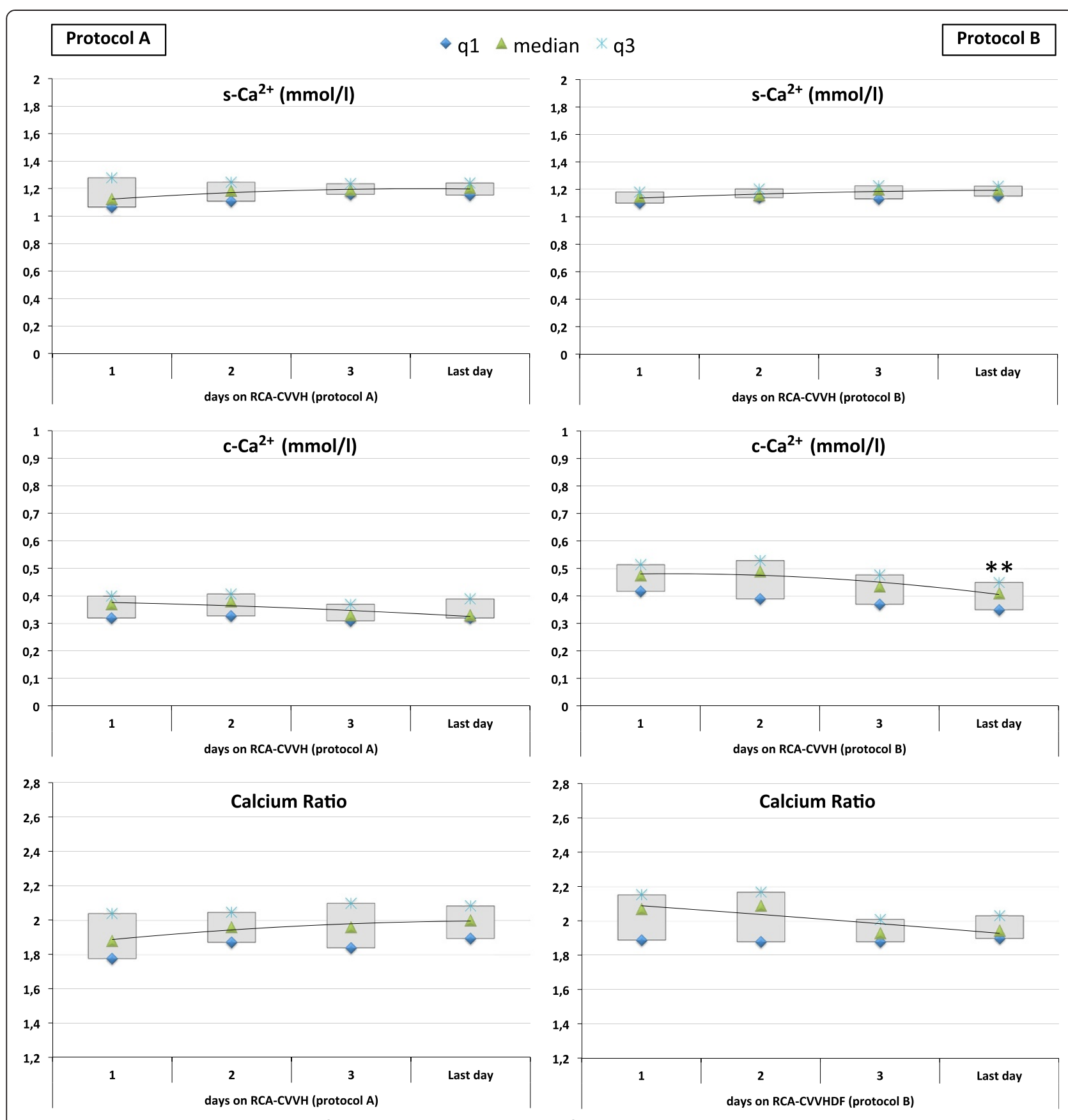

Figure 3 Systemic ionized calcium $\left(\mathrm{s}-\mathrm{Ca}^{2+}\right)$, circuit ionized calcium $\left(\mathrm{c}-\mathrm{Ca}^{2+}\right)$ and Calcium Ratio throughout RCA-CRRT days with the two different protocols. Data for protocol $A$ (left panels) and protocol $B$ (right panels) are displayed as median and interquartile range $(q 1$ to $q 3) .{ }^{* *} p<0.02$.

For this reason, additional bicarbonate infusion was required in most of the patients (90\%). Thus, in our experience, the combination of a very low citrate concentration solution $(10 \mathrm{mmol} / \mathrm{l}$ trisodium citrate, $2 \mathrm{mmol} / \mathrm{l}$ citric acid) with a conventional bicarbonate replacement fluid (32 $\mathrm{mmol} / \mathrm{l}$ ) does not allow to tailor buffer delivery according to patient' needs. This problem cannot be easily overcome by an increase of pre-dilution citrate flow rate, which invariably results in a significant increase of effluent rate with the consequent loss of more citrate and bicarbonate in the ultrafiltrate. Thus, any increment in citrate dose does not result in a clinically significant increment of buffers delivery to the patient. Comparable findings, regarding the persistence of mild metabolic acidosis and the need for additional bicarbonate, have been reported by Hetzel et al., performing CVVH with a $13 \mathrm{mmol} / \mathrm{l}$ citrate solution [18], and by Shum et al., adopting $\mathrm{CVVH}$ with a $12 \mathrm{mmol} / \mathrm{l}$ citrate solution combined with pre-filter 
Table 4 Laboratory variables and supplementation needs during RCA-CRRT

\begin{tabular}{|c|c|c|c|}
\hline Variable & Protocol A $(n=20)$ & Protocol B $(n=20)$ & $P$ value \\
\hline Systemic $\mathrm{Ca}^{2+}, \mathrm{mmol} / \mathrm{l}$ & $1.16(1.10-1.23)$ & $1.16(1.11-1.21)$ & 0.995 \\
\hline Total Calcium, mmol// & $2.33(2.20-2.50)$ & $2.33(2.21-2.45)$ & 0.474 \\
\hline Calcium Ratio & $1.95(1.84-2.09)$ & 1.98 (1.89-2.09) & 0.296 \\
\hline Circuit $\mathrm{Ca}^{2+}, \mathrm{mmol} / \mathrm{l}$ & $0.37(0.32-0.40)$ & $0.42(0.36-0.47)$ & $<0.001$ \\
\hline Sodium, mmol/l & $134(133-136)$ & $134(132-135)$ & 0.213 \\
\hline Potassium, mmol/l & $4.2(4.0-4.3)$ & $4.2(4.0-4.4)$ & 0.159 \\
\hline Phosphate, mmol/l & $0.70(0.50-1.00)$ & $1.20(0.97-1.45)$ & $<0.001$ \\
\hline Magnesium, mmol// & $0.78(0.58-0.95)$ & $0.79(0.73-0.84)$ & $<0.001$ \\
\hline $\mathrm{pH}$, units & $7.40(7.36-7.44)$ & $7.43(7.40-7.46)$ & $<0.001$ \\
\hline Bicarbonate, mmol/l & $22.1(20.9-23.5)$ & $25.3(23.8-26.6)$ & $<0.001$ \\
\hline Base Excess & $-3.1(-4.6$ to -1.1$)$ & 0.9 (-0.8 to 2.4$)$ & $<0.001$ \\
\hline $\mathrm{pCO}_{2}, \mathrm{mmHg}$ & $35(32-41)$ & $38(35-40)$ & 0.527 \\
\hline Apparent strong ion difference (AppSID), mEq/l & $37.6(36.1-39.4)$ & $39.1(37.9-40.2)$ & $<0.001$ \\
\hline Effective strong ion difference (EffSID), mEq/l & $32.0(30.6-33.1)$ & $34.3(32.8-35.9)$ & $<0.001$ \\
\hline Strong ion gap (SIG), mEq/l & $5.8(3.5-7.7)$ & $4.5(3.1-6.9)$ & 0.585 \\
\hline Lactate, mmol/l & $1.2(0.9-1.6)$ & $1.1(0.8-1.4)$ & $<0.001$ \\
\hline Platelet count, $\times 10^{3} / \mu \mathrm{l}$ & $90(53-156)$ & $187(121-261)$ & $<0.001$ \\
\hline Antithrombin III activity, $\%$ & $72(62-81)$ & $75(63-89)$ & 0.078 \\
\hline aPTT Ratio & $1.4(1.3-1.6)$ & $1.4(1.2-1.7)$ & 0.575 \\
\hline \multicolumn{4}{|l|}{ Supplementation needs } \\
\hline $\mathrm{CaCl}_{2}$ infusion, $\mathrm{mmol} / \mathrm{h}$ & $2.18(1.90-2.45)$ & $2.24(1.97-2.58)$ & 0.800 \\
\hline $\mathrm{KCl}$ infusion, mmol/h & $5(3-7)$ & $2(0-4)$ & $<0.001$ \\
\hline Magnesium Sulphate, g/day & $3(2-3)$ & $3(3-3)$ & $<0.001$ \\
\hline Need for bicarbonate infusion, n (\%) & 18/20 (90\%) & $0 / 20(0 \%)$ & $<0.001$ \\
\hline Infusion rate, $\mathrm{mmol} / \mathrm{h}$ & $6 \pm 6.4$ & No supplementation & \\
\hline Need for phosphate supplementation, n (\%) & $20 / 20(100 \%)$ & $6 / 20(30 \%)$ & $<0.001$ \\
\hline $\mathrm{g}$ of phosphorus/day & $3.39 \pm 2.45$ & $0.52 \pm 1.53$ & \\
\hline
\end{tabular}

Data are expressed as median (IQR) or mean \pm SD or percentage.

infusion of a highly concentrated bicarbonate solution (8.4\%) to obtain a more positive buffers balance [39]. However, other authors obtained an appropriate acid-base balance with the use of a slightly higher concentration citrate solution $(13.3 \mathrm{mmol} / \mathrm{l})$, without the need of additional bicarbonate infusion [40,41].

In the present study, the adoption of an $18 \mathrm{mmol} / \mathrm{l} \mathrm{cit-}$ rate solution (protocol B) allowed to more efficiently meet patient' buffer requirements maintaining, at the same time, a citrate load comparable to protocol $A$. Indeed, in the protocol $B$ patients, acid-base status was adequately maintained without additional interventions and both serum bicarbonate levels and $\mathrm{pH}$ values were significantly higher to that achieved, despite bicarbonate infusion, in patients undergoing RCA-CVVH with protocol $A$.

The use of an $18 \mathrm{mmol} / \mathrm{l}$ citrate solution is not new and has been previously introduced in CVVHDF by Tolwani et al. [22]. Comparing two different citrate solutions during
RCA, with the aim to optimize buffers mass balance, the Authors found that the adoption of a citrate concentration of $23 \mathrm{mmol} / \mathrm{l}$ was associated with a high incidence of metabolic alkalosis (18 out of 24 patients) while the use of an $18 \mathrm{mmol} / \mathrm{l}$ solution was able to provide an appropriate acid-base balance in most of the patients, although at some point during CRRT alkalosis still occurred in 9 out of 32 patients. However, both protocols required a custom-made dialysate with a lower than usual bicarbonate concentration ( $25 \mathrm{mmol} / \mathrm{l})$ [22]. These findings raised our attention about the risk of alkalosis, possibly enhanced by the standard bicarbonate CRRT solution $(30 \mathrm{mmol} / \mathrm{l})$ adopted in protocol $B$ as dialysate and post-dilution replacement fluid. Therefore, in order to prevent buffers overload related to the combination of the solutions adopted, we accepted a higher than usual $\mathrm{c}-\mathrm{Ca}^{2+}$ target $(\leq 0.5 \mathrm{mmol} / \mathrm{l})$ with the aim to minimize the need for any increment of citrate dose throughout RCA-CRRT days. Thus, despite initial 


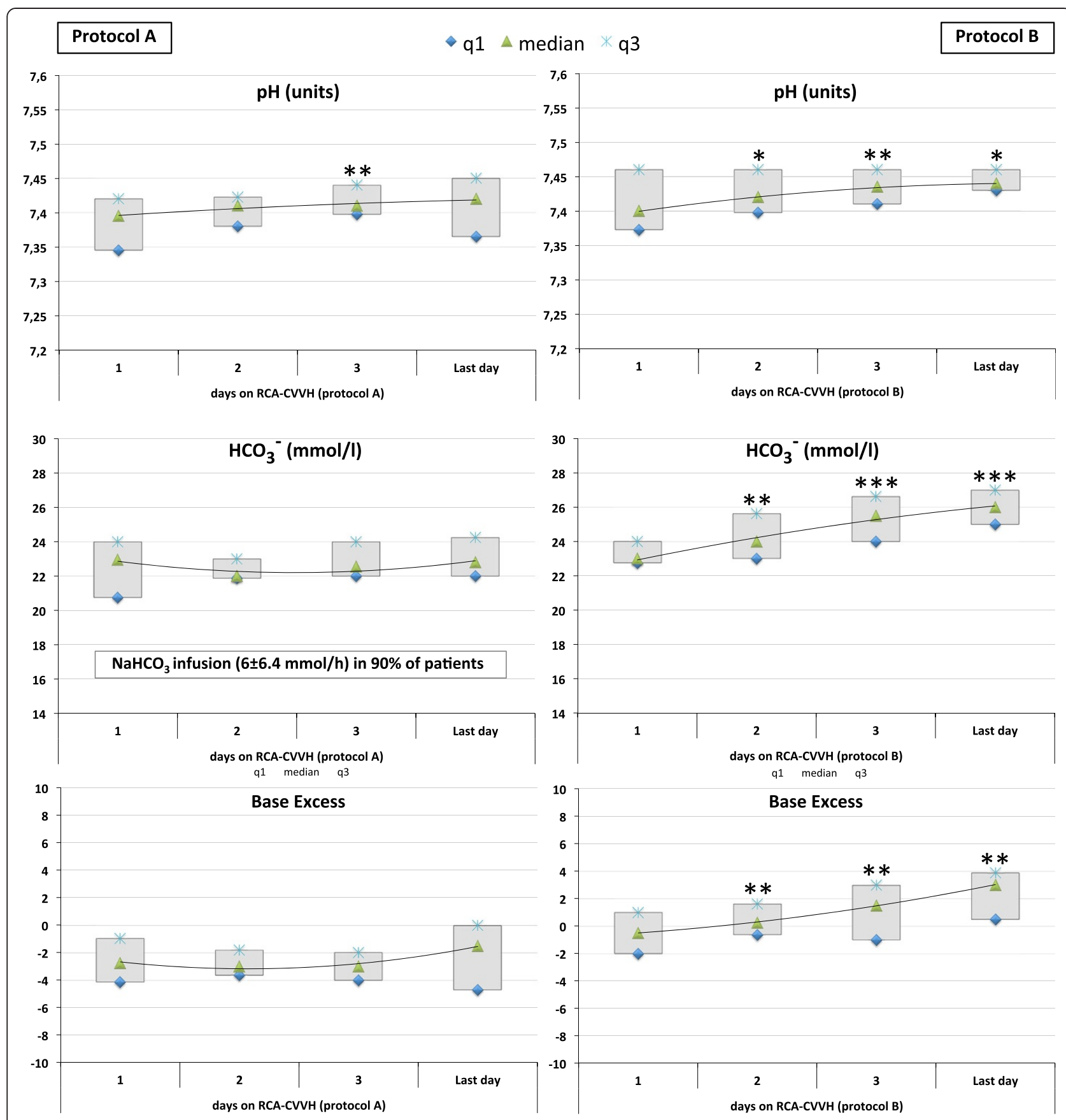

Figure 4 Main acid-base parameters throughout RCA-CRRT days with the two different protocols. Data for protocol A (left panels) and protocol $B$ (right panels) are displayed as median and interquartile range (q1 to $q 3$ ). ${ }^{*} p<0.05,{ }^{* *} p<0.02,{ }^{* * *} p<0.001$.

concerns, protocol B afforded an appropriate acid-base balance without occurrence of clinically significant metabolic alkalosis. In summary, although these findings need to be confirmed in a more consistent number of patients and in a wider range of clinical situations, the solutions combination adopted in protocol $B$ appears to be at low risk of acid-base derangements and represents, in our opinion, a step forward if compared to protocol A.
By shifting to protocol B, our purpose was also to simplify RCA-CRRT handling and to reduce the need for additional infusions. In particular, we aimed at minimizing CRRT-induced phosphate depletion [42] through the combination of the citrate solution with a recently introduced, commercially available, phosphate-containing CRRT solution, acting as dialysate and post-dilution replacement fluid. In this regard, although the prognostic 


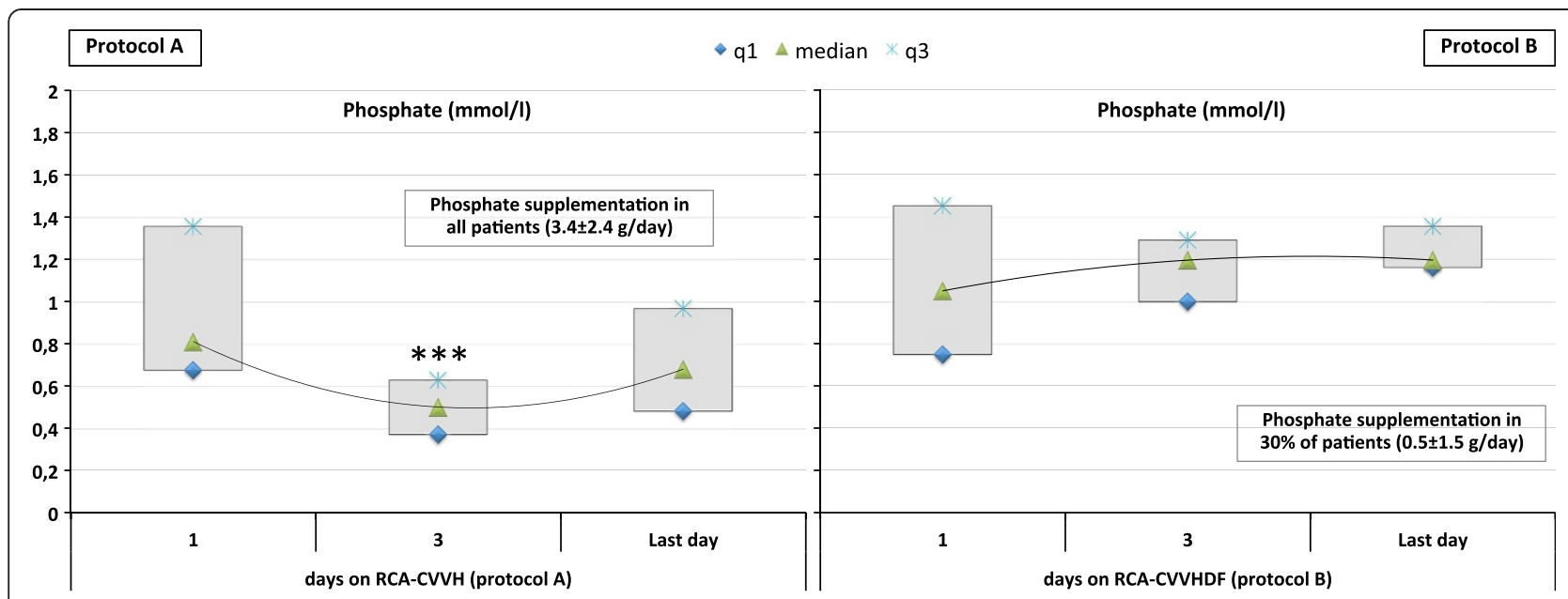

Figure 5 Serum phosphate and need for phosphorus supplementation throughout RCA-CRRT days with the two different protocols. Data for protocol $A$ (left panel) and protocol $B$ (right panel) are displayed as median and interquartile range (q1 to $q 3$ ). ${ }^{* * *} p<0.001$.

significance of mild to moderate serum phosphate disturbances in critically ill patients is still a matter of discussion [43], it is well known that severe hypophosphatemia can cause generalized muscle weakness and even paralysis of the respiratory muscles, myocardial dysfunction, reduced peripheral vascular resistance and encephalopathy [44]. Therefore, in patients undergoing CRRT, it could be appropriate to prevent hypophosphatemia by addition of phosphate to the replacement and/ or dialysate solutions. To this purpose, the feasibility and safety of phosphate addition to conventional dialysate and replacement fluids have been successfully tested in adult and pediatric patients undergoing CRRT $[25,28]$. More recently, the efficacy of a commercially available phosphate-containing solution in preventing hypophosphatemia has been reported in patients undergoing CVVHDF [30] or CVVH [31]. However, Chua et al. underlined that the switch to a phosphatecontaining solution as the sole replacement fluid for CVVH could contribute to mild hyperphosphatemia and could be associated with metabolic acidosis, possibly related to fluid composition [32]. In our RCA-CVVHDF protocol, we adopted the same phosphate-containing solution but it accounted for about $50 \%$ of total CRRT dose and, as discussed above, its adoption in combination with an $18 \mathrm{mmol} / \mathrm{l}$ citrate solution was not associated with acid-base derangements. Furthermore, as intended, the introduction of the phosphate-containing solution appeared effective to prevent hypophosphatemia in $70 \%$ of protocol $B$ patients; in the remaining cases, the occurrence of a mild to moderate hypophosphatemia was easily overwhelmed by an amount of phosphorus supplementation much lower than that constantly required in all patients undergoing $\mathrm{RCA}-\mathrm{CVVH}$ with protocol $A$. In addition, serum phosphate was significantly higher in protocol $B$ patients and appeared to be steadily maintained in a narrower range throughout the entire RCA-CVVHDF treatment period without occurrence of clinically relevant hyperphosphatemia. On the contrary, as documented by the presence of hypophosphatemia in more than $40 \%$ of determinations, the strategy of parenteral phosphorus supplementation adopted for protocol $A$ was associated with wide-ranging variations of phosphatemia during RCA-CVVH. These findings confirm the efficacy of phosphate-containing solutions in reducing the incidence of CRRT-induced hypophosphatemia, already reported elsewhere during conventional CRRT $[25,28,30,31]$, adding useful information about its use in the context of RCA and extending the results of a single-case preliminary experience recently reported by our own group [24]. Lastly, in comparison to most of the protocols reported elsewhere, the adoption of a calcium-containing CRRT solution, which characterizes both protocols, allowed us to reduce $\mathrm{CaCl}_{2}$ infusion requirement and to minimize the risk of errors in bags handling related to the use of "zero" calcium solutions.

\section{Conclusions}

In conclusion, the proposed RCA-CVVHDF protocol, using an $18 \mathrm{mmol} / \mathrm{l}$ citrate solution, provided a more adequate control of acid-base status if compared to the previously adopted $12 \mathrm{mmol} / \mathrm{l} \mathrm{RCA}-\mathrm{CVVH}$ protocol. The adoption of a low citrate dose, particularly useful in patients with high severity scores, and the maintenance of a higher than usual target circuit $\mathrm{Ca}^{2+}$ were still associated with an adequate circuit lifetime and with a very low incidence of clotting as cause of CRRT stopping. Finally, the novel adoption of a phosphate-containing solution, in the setting of RCA, allowed to prevent CRRT-induced 
hypophosphatemia in most of the patients, minimizing the need for phosphorus supplementation.

\section{Competing interests}

The authors declare that they have no competing interests.

\section{Authors' contributions}

SM and VP were involved in the conception, design, analysis and interpretation of data, drafting the article and revising it critically for important intellectual content and final approval of the version to be published. LT was involved in revising the manuscript for important intellectual content and final approval. EV contributes to the design and optimization of RCA-CWH protocols. LZ and FP provided substantial contributions to data collection. EF and AP contributed to the interpretation of data and critically revised the manuscript for important intellectual content and final approval. SM and VP contributed equally to the work and are both considered first authors. All authors read and approved the final manuscript.

\section{Acknowledgements}

The authors thank the nursing and medical staff (dialysis and ICU), Department of Nephrology and Urology, Hemodialysis Unit, and Postoperative Intensive Care Unit, Department of Cardiac Surgery, at Umberto I Hospital, "Sapienza" University of Rome, for their support and cooperation in running a successful CRRT program.

\section{Author details}

'Department of Nephrology and Urology, Hemodialysis Unit, Umberto I, Policlinico di Roma, "Sapienza" University, Rome, Italy. "Department of Anesthesiology and Intensive Care, Cardiac Surgery ICU, Umberto I, Policlinico di Roma, "Sapienza" University, Rome, Italy. ${ }^{3}$ Division of Nephrology and Dialysis, Pertini Hospital, Rome, Italy. ${ }^{4}$ Department of Clinical and Experimental Medicine, Acute and Chronic Renal Failure Unit, Parma University, Parma, Italy.

Received: 16 May 2013 Accepted: 22 October 2013

Published: 25 October 2013

\section{References}

1. Uchino S, Bellomo R, Morimatsu H, Morgera S, Schetz M, Tan I, Bouman C, Macedo E, Gibney N, Tolwani A, Oudemans-van Straaten H, Ronco C, Kellum JA: Continuous renal replacement therapy: a worldwide practice survey. The beginning and ending supportive therapy for the kidney (B.E.S.T. kidney) investigators. Intensive Care Med 2007, 33:1563-1570.

2. Ronco C, Bellomo R: Dialysis in intensive care unit patients with acute kidney injury: continuous therapy is superior. Clin J Am Soc Nephrol 2007, 2:597-600.

3. Legrand M, Darmon M, Joannidis M, Payen D: Management of renal replacement therapy in ICU patients: an international survey. Intensive Care Med 2013, 39:101-108.

4. Mehta RL: Anticoagulation during continuous renal replacement therapies. ASAIO J 1994, 40:931-935.

5. Van de Wetering J, Westendorp RG, van der Hoeven JG, Stolk B, Feuth JD, Chang PC: Heparin use in continuous renal replacement procedures: the struggle between filter coagulation and patient hemorrhage. J Am Soc Nephrol 1996, 7:145-150.

6. Kidney Disease Improving Global Outcomes (KDIGO) Acute Kidney Injury Work Group: KDIGO clinical practice guideline for acute kidney injury. Kidney Int 2012, 2(Suppl):1-138.

7. Fiaccadori E, Maggiore U, Clima B, Melfa L, Rotelli C, Borghetti A: Incidence, risk factors, and prognosis of gastrointestinal hemorrhage complicating acute renal failure. Kidney Int 2001, 59:1510-1519.

8. Davenport A, Tolwani A: Citrate anticoagulation for continuous renal replacement therapy (CRRT) in patients with acute kidney injury admitted to the intensive care unit. NDT Plus 2009, 2:439-447.

9. Oudemans-van Straaten HM, Kellum JA, Bellomo R: Clinical review: anticoagulation for continuous renal replacement therapy-heparin or citrate? Crit Care 2011, 15:202.

10. Morabito S, Pistolesi V, Pierucci A: Regional citrate anticoagulation: towards a first-choice treatment. G Ital Nefrol 2012, 29:14-19.
11. Zhang Z, Hongying N: Efficacy and safety of regional citrate anticoagulation in critically ill patients undergoing continuous renal replacement therapy. Intensive Care Med 2012, 38:20-28.

12. Wu MY, Hsu YH, Bai CH, Lin YF, Wu CH, Tam KW: Regional citrate versus heparin anticoagulation for continuous renal replacement therapy: a meta-analysis of randomized controlled trials. Am J Kidney Dis 2012, 59:810-818.

13. Oudemans-van Straaten HM, Ostermann M: Bench-to-bedside review: citrate for continuous renal replacement therapy, from science to practice. Crit Care 2012, 16:249.

14. Monchi M, Berghmans D, Ledoux D, Canivet JL, Dubois B, Damas P: Citrate vs. heparin for anticoagulation in continuous venovenous hemofiltration: a prospective randomized study. Intensive Care Med 2004, 30:260-265.

15. Kutsogiannis DJ, Gibney RT, Stollery D, Gao J: Regional citrate versus systemic heparin anticoagulation for continuous renal replacement in critically ill patients. Kidney Int 2005, 67:2361-2367.

16. Betjes MG, van Oosterom D, van Agteren M, van de Wetering J: Regional citrate versus heparin anticoagulation during venovenous hemofiltration in patients at low risk for bleeding: similar hemofilter survival but significantly less bleeding. J Nephrol 2007, 20:602-608.

17. Oudemans-van Straaten HM, Bosman RJ, Koopmans M, van der Voort PH, Wester JP, van der Spoel JI, Dijksman LM, Zandstra DF: Citrate anticoagulation for continuous venovenous hemofiltration. Crit Care Med 2009, 37:545-552.

18. Hetzel GR, Schmitz M, Wissing H, Ries W, Schott G, Heering PJ, Isgro F, Kribben A, Himmele R, Grabensee B, Rump LC: Regional citrate versus systemic heparin for anticoagulation in critically ill patients on continuous venovenous haemofiltration: a prospective randomized multicentre trial. Nephrol Dial Transplant 2011, 26:232-239.

19. Morabito S, Pistolesi V, Tritapepe L, Zeppilli L, Polistena F, Strampelli E, Pierucci A: Regional citrate anticoagulation in cardiac surgery patients at high risk of bleeding: a continuous veno-venous hemofiltration protocol with a low concentration citrate solution. Crit Care 2012, 16:R111.

20. Abramson S, Niles JL: Anticoagulation in continuous renal replacement therapy. Curr Opin Nephrol Hypertens 1999, 8:701-707.

21. Mariano F, Morselli M, Bergamo D, Hollo Z, Scella S, Maio M, Tetta C, Dellavalle A, Stella M, Triolo G: Blood and ultrafiltrate dosage of citrate as a useful and routine tool during continuous venovenous haemodiafiltration in septic shock patients. Nephrol Dial Transplant 2011, 26:3882-3888.

22. Tolwani AJ, Prendergast MB, Speer RR, Stofan BS, Wille KM: A practical citrate anticoagulation continuous venovenous hemodiafiltration protocol for metabolic control and high solute clearance. Clin J Am Soc Nephrol 2006, 1:79-87.

23. Morgera S, Schneider M, Slowinski T, Vargas-Hein O, Zuckermann-Becker $H$ Peters $\mathrm{H}$, Kindgen-Milles D, Neumayer HH: A safe citrate anticoagulation protocol with variable treatment efficacy and excellent control of the acid-base status. Crit Care Med 2009, 37:2018-2024.

24. Morabito S, Pistolesi V, Tritapepe L, Zeppilli L, Polistena F, Fiaccadori E, Pierucci A: Regional citrate anticoagulation in $\mathrm{CVVH}$ : a new protocol combining citrate solution with a phosphate-containing replacement fluid. Hemodial Int 2013, 17:313-320.

25. Troyanov S, Geadah D, Ghannoum M, Cardinal J, Leblanc M: Phosphate addition to hemodiafiltration solutions during continuous renal replacement therapy. Intensive Care Med 2004, 30:1662-1665.

26. VA/NIH Acute Renal Failure Trial Network, Palevsky PM, Zhang JH, O'Connor TZ, Chertow GM, Crowley ST, Choudhury D, Finkel K, Kellum JA, Paganini E, Schein RM, Smith MW, Swanson KM, Thompson BT, Vijayan A, Watnick S, Star RA, Peduzzi P: Intensity of renal support in critically ill patients with acute kidney injury. N Engl J Med 2008, 359:7-20.

27. RENAL Replacement Therapy Study Investigators, Bellomo R, Cass A, Cole L, Finfer S, Gallagher M, Lo S, McArthur C, McGuinness S, Myburgh J, Norton R, Scheinkestel C, Su S: Intensity of continuous renal-replacement therapy in critically ill patients. N Engl J Med 2009, 361:1627-1638.

28. Santiago MJ, López-Herce J, Urbano J, Bellón JM, del Castillo J, Carrillo A: Hypophosphatemia and phosphate supplementation during continuous renal replacement therapy in children. Kidney Int 2009, 75:312-316.

29. Demirjian S, Teo BW, Guzman JA, Heyka RJ, Paganini EP, Fissell WH, Schold $J D$, Schreiber MJ: Hypophosphatemia during continuous hemodialysis is associated with prolonged respiratory failure in patients with acute kidney injury. Nephrol Dial Transplant 2011, 26:3508-3514. 
30. Broman M, Carlsson O, Friberg H, Wieslander A, Godaly G: Phosphatecontaining dialysis solution prevents hypophosphatemia during continuous renal replacement therapy. Acta Anaesthesiol Scand 2011, 55:39-45.

31. Chua HR, Baldwin I, Ho L, Collins A, Allsep H, Bellomo R: Biochemical effects of phosphate-containing replacement fluid for continuous venovenous hemofiltration. Blood Purif 2012, 34:306-312.

32. Whitfield LR, Levy G: Permeability of human and rat red blood cells to citrate. Thromb Res 1981, 21:681-684.

33. Kozik-Jaromin J, Nier V, Heemann U, Kreymann B, Bohler J: Citrate pharmacokinetics and calcium levels during high-flux dialysis with regional citrate anticoagulation. Nephrol Dial Transplant 2009, 24:2244-2251.

34. Hetzel GR, Taskaya G, Sucker C, Hennersdorf M, Grabensee B, Schmitz M: Citrate plasma levels in patients under regional anticoagulation in continuous venovenous hemofiltration. Am J Kidney Dis 2006, 48:806-811.

35. Mariano F, Tedeschi L, Morselli M, Stella M, Triolo G: Normal citratemia and metabolic tolerance of citrate anticoagulation for hemodiafiltration in severe septic shock burn patients. Intensive Care Med 2010, 36:1735-1743.

36. Bakker AJ, Boerma EC, Keidel H, Kingma P, van der Voort PH: Detection of citrate overdose in critically ill patients on citrate-anticoagulated venovenous haemofiltration: use of ionised and total/ionised calcium. Clin Chem Lab Med 2006, 44:962-966.

37. Schultheiß C, Saugel B, Phillip V, Thies P, Noe S, Mayr U, Haller B, Einwachter $\mathrm{H}$, Schmid RM, Huber W: Continuous venovenous hemodialysis with regional citrate anticoagulation in patients with liver failure: a prospective observational study. Crit Care 2012, 16:R162

38. Link A, Klingele M, Speer T, Rbah R, Poss J, Lerner-Graber A, Fliser D, Bohm $\mathrm{M}$ : Total-to-ionized calcium ratio predicts mortality in continuous renal replacement therapy with citrate anticoagulation in critically ill patients. Crit Care 2012, 16:R97.

39. Shum HP, Chan KC, Yan WW: Regional citrate anticoagulation in predilution continuous venovenous hemofiltration using prismocitrate 10/2 solution. Ther Apher Dial 2012, 16:81-86.

40. Aman J, Nurmohamed SA, Vervloet MG, Groeneveld AB: Metabolic effects of citrate- vs bicarbonate-based substitution fluid in continuous venovenous hemofiltration: a prospective sequential cohort study. J Crit Care 2010, 25:120-127.

41. Nurmohamed SA, Jallah BP, Vervloet MG, Yldirim G, ter Wee PM, Groeneveld $A B$ : Continuous venovenous haemofiltration with citrate-buffered replacement solution is safe and efficacious in patients with a bleeding tendency: a prospective observational study. BMC Nephrol 2013, 14:89.

42. Fiaccadori E, Maggiore U, Cabassi A, Morabito S, Castellano G, Regolisti G: Nutritional evaluation and management of AKI patients. J Ren Nutr 2013, 23:255-258.

43. Suzuki S, Egi M, Schneider AG, Bellomo R, Hart GK, Hegarty C: Hypophosphatemia in critically ill patients. J Crit Care 2013, 28:536

44. Bugg NC, Jones JA: Hypophosphataemia. Pathophysiology, effects and management on the intensive care unit. Anaesthesia 1998, 53:895-902.

doi:10.1186/1471-2369-14-232

Cite this article as: Morabito et al:: Continuous venovenous hemodiafiltration with a low citrate dose regional anticoagulation protocol and a phosphate-containing solution: effects on acid-base status and phosphate supplementation needs. BMC Nephrology 2013 14:232.

\section{Submit your next manuscript to BioMed Central and take full advantage of:}

- Convenient online submission

- Thorough peer review

- No space constraints or color figure charges

- Immediate publication on acceptance

- Inclusion in PubMed, CAS, Scopus and Google Scholar

- Research which is freely available for redistribution 